\title{
Cardiac implantable electronic device infection due to Mycobacterium species: a case report and review of the literature
}

\author{
Bandar Al-Ghamdi ${ }^{1,3}$, Hassan El Widaa', Maie Al Shahid ${ }^{1}$, Mohammed Aladmawi $^{1}$, Jawaher Alotaibi², \\ Aly Al Sanei ${ }^{1}$ and Magid Halim ${ }^{2,3}$
}

\begin{abstract}
Background: Infection of cardiac implantable electronic devices is a serious cardiovascular disease and it is associated with a high mortality. Mycobacterium species may rarely cause cardiac implantable electronic devices infection.

Case presentation: We are reporting a case of miliary tuberculosis in an Arab patient with dilated cardiomyopathy and a cardiac resynchronization therapy-defibrillator device that was complicated with infection of his cardiac resynchronization therapy-defibrillator device. To our knowledge, this is the third case in the literature with such a presentation and all patients died during the course of treatment. This underscores the importance of early diagnosis and management. We also performed a literature review of reported cases of cardiac implantable electronic devices infection related to Mycobacterium species.
\end{abstract}

Conclusions: Cardiac implantable electronic devices infection due to Mycobacterium species is an uncommon but a well-known entity. Early diagnosis and prompt management may result in a better outcome.

Keywords: Mycobacterium, Pacemaker, Defibrillator, Infection, Endocarditis

\section{Background}

Infection of cardiac implantable electronic devices (CIEDs) is a serious cardiovascular disease and it is associated with a high mortality. CIEDs infection may occur as a pocket infection or as infection on the leads with infective endocarditis. Cardiac device-related infective endocarditis (CDR-IE) may occur as a primary infection of the CIED system or as a secondary infection as a result of hematogenous seeding during a bacteremia secondary to a distant infected focus [1].

Mycobacterium tuberculosis (TB) is an infection that primarily affects the lungs, but it can involve any other organs and structures such as the kidney, spine, brain, and rarely the heart. TB disease can be fatal if not treated properly (http://www.cdc.gov).

*Correspondence: balghamdi@kfshrc.edu.sa

${ }^{1}$ Heart Centre, King Faisal Specialist Hospital and Research Centre

(KFSH\&RC), MBC-16, PO Box 3354, Riyadh 11211, Saudi Arabia

Full list of author information is available at the end of the article
Tuberculosis endocarditis (TBE) has been reported for many years with involvement of native or prosthetic valves mostly in cases of miliary TB [2]. Mycobacterium species are another uncommon but well-described pathogen in CIED infections [3].

We are reporting a case of miliary TB in an Arab patient with dilated cardiomyopathy and a cardiac resynchronization therapy-defibrillator (CRT-D) device. His condition was complicated with TB meningitis and a CDR-IE with vegetations on the leads. He underwent surgical removal of the CRT-D device and leads and a gram stain of the vegetations was positive for acid-fast bacilli (AFB). We also performed a literature review of reported cases with Mycobacterium species related CIEDs infection.

\section{Case presentation}

A 50-year-old male Arab patient with non-ischemic dilated cardiomyopathy, biventricular failure with left ventricular ejection fraction (LVEF) of $20 \%$, moderate to severe mitral regurgitation and tricuspid regurgitation, 
left bundle branch block, and non-sustained ventricular tachycardia. Cardiac catheterization did not show any significant coronary artery disease. He underwent a CRT-D device implantation, as he was symptomatic with shortness of breath, New York Heart Association Functional Classification-II. He had no history of diabetes mellitus, hypertension, or dyslipidemia. He was on antiheart failure medications and was on the heart transplantation list.

He presented to the Emergency Department 8 months after CRT-D device implantation with 2 months' history of high-grade fever, chills, rigors, and weight loss. There was no history of concomitant respiratory, gastroenterology, cardiovascular, or neurologic localizing symptoms. There was no history of contact with febrile or TB patients. He was seen at another medical center and started on intravenous (IV) vancomycin and gentamicin for possible infective endocarditis involving his CRT-D device leads but with no improvement.

On presentation, he was looking chronically ill but not in acute distress. He was febrile with a temperature of $38.8^{\circ} \mathrm{C}$, but he was hemodynamically stable with a blood pressure of $107 / 57 \mathrm{~mm} \mathrm{Hg}$, and heart rate of 98 beats per minute. Oxygen saturation was $92-94 \%$ on room air. Cardiovascular exam showed a jugular venous pressure (JVP) at $4 \mathrm{~cm}$ above the sternal angle; normal first and second heart sounds with a soft systolic murmur at left lower sternal border which was reported in his previous physical exam. The device site in the left upper chest was normal. There was no lower limb edema and no stigmata of infective endocarditis. Chest exam showed bilateral basal crepitations. Neurological exam was unremarkable.

Laboratory tests; $\mathrm{CBC}$ showed mild anemia, and thrombocytopenia with normal white blood count. Renal profile was normal and hepatic profile showed mild elevation of aspartate aminotransferase (AST) and total bilirubin, and low albumin. Cardiac enzymes showed mild elevation of Troponin T. Lactic acid was elevated. Laboratory test values are summarized in Table 1 . The 12 lead electrocardiogram showed sinus tachycardia at 106 beats per minute with atrial sensed and biventricular paced rhythm.

The chest X-ray showed a diffuse miliary shadowing in both lungs suggestive of tuberculosis. There was mild ground-glass attenuation, especially in the right paracardiac region. The heart was normal in size with CRT-D leads in place. There was no pleural effusion seen (Fig. 1).

The high-resolution computed tomography (CT) chest was consistent with miliary TB. There was no axillary, hilar or mediastinal lymphadenopathy (Fig. 2).

Based on the clinical presentation, the chest X-ray and CT chest findings, he was started on first-line antiTB therapy in the form of rifampin $600 \mathrm{mg}$ orally once
Table 1 Laboratory test results on admission

\begin{tabular}{|c|c|c|}
\hline Test & Patient's value & Normal range \\
\hline \multicolumn{3}{|l|}{ CBC } \\
\hline WBC & $6.1110^{9} / \mathrm{L}$ & $3.90-11.00$ \\
\hline $\mathrm{Hb}$ & $107 \mathrm{~g} / \mathrm{L}$ & $135-180$ \\
\hline Hct & $0.311 \mathrm{~L} / \mathrm{L}$ & $0.370-0.520$ \\
\hline PLT & $8910^{9} / \mathrm{L}$ & $155-435$ \\
\hline \multicolumn{3}{|l|}{ Renal profile } \\
\hline Urea & $5.2 \mathrm{mmol} / \mathrm{L}$ & $2.5-7.5$ \\
\hline Creatinine & $75 \mathrm{umol} / \mathrm{L}$ & $64-115$ \\
\hline e-GFR & $>60 \mathrm{~mL} / \mathrm{min} / 1.73 \mathrm{~m}^{2}$ & $>60$ \\
\hline Potassium & $3.6 \mathrm{mmol} / \mathrm{L}$ & $3.5-5.0$ \\
\hline Sodium & $124 \mathrm{mmol} / \mathrm{L}$ & $134-147$ \\
\hline Chloride & $94 \mathrm{mmol} / \mathrm{L}$ & $98-111$ \\
\hline \multicolumn{3}{|l|}{ Liver function test } \\
\hline ALT & $15 U / L$ & $10-45$ \\
\hline AST & $64.2 \mathrm{U} / \mathrm{L}$ & $10-45$ \\
\hline Albumin & $25 \mathrm{~g} / \mathrm{L}$ & $32-48$ \\
\hline Total bilirubin & $29 \mathrm{umol} / \mathrm{L}$ & $0.0-21.0$ \\
\hline \multicolumn{3}{|l|}{ Glucose } \\
\hline Random glucose & $5.60 \mathrm{mmol} / \mathrm{L}$ & $2.7-18.0$ \\
\hline \multicolumn{3}{|l|}{ Cardiac enzymes } \\
\hline CK & $83 \mathrm{U} / \mathrm{L}$ & 24-195 \\
\hline Troponin T & 0.022 ug/L & $0.01-0.10$ \\
\hline \multicolumn{3}{|l|}{ Others } \\
\hline $\mathrm{CO}_{2}$ & $18 \mathrm{mmol} / \mathrm{L}$ & $22-31$ \\
\hline Lactic acid & $3.93 \mathrm{mmol} / \mathrm{L}$ & $0.9-1.8$ \\
\hline
\end{tabular}

CBC Complete blood count; WBC White blood cell count; $H b$ Hemoglobin; Hct Hematocrit; PLT Platelets; e-GFR estimated Glomerular filtration rate; CK Creatine kinase; $\mathrm{CO}_{2}$ Carbon dioxide

daily, ethambutol $1200 \mathrm{mg}$ orally once daily, pyrazinamide $2000 \mathrm{mg}$ orally once daily, and isoniazid (isonicotinylhydrazide or INH) $300 \mathrm{mg}$ orally once daily, with the addition of vitamin B6 $25 \mathrm{mg}$ orally once daily, and prednisone $60 \mathrm{mg}$ orally once daily.

The trans-thoracic echocardiogram showed moderately dilated LV with severe global hypokinesis and severely reduced function (LVEF $<25 \%$ ). The CRT-D device leads were seen in the right atrium and right ventricle. There were no obvious masses on the leads or on any of the cardiac valves to suggest vegetations. There was mild to moderate mitral regurgitation. The right ventricular systolic pressure was elevated at $30-40 \mathrm{mmHg}$. There was no pericardial effusion.

The transesophageal echocardiogram was performed, and it showed a mass in the superior vena cava (SVC) around the CRT-D device leads, extending into the right atrium (RA). A thin flickering structure consistent with a remnant of a Eustachian valve or Chiari network was also noted. No masses were seen on them to suggest free 


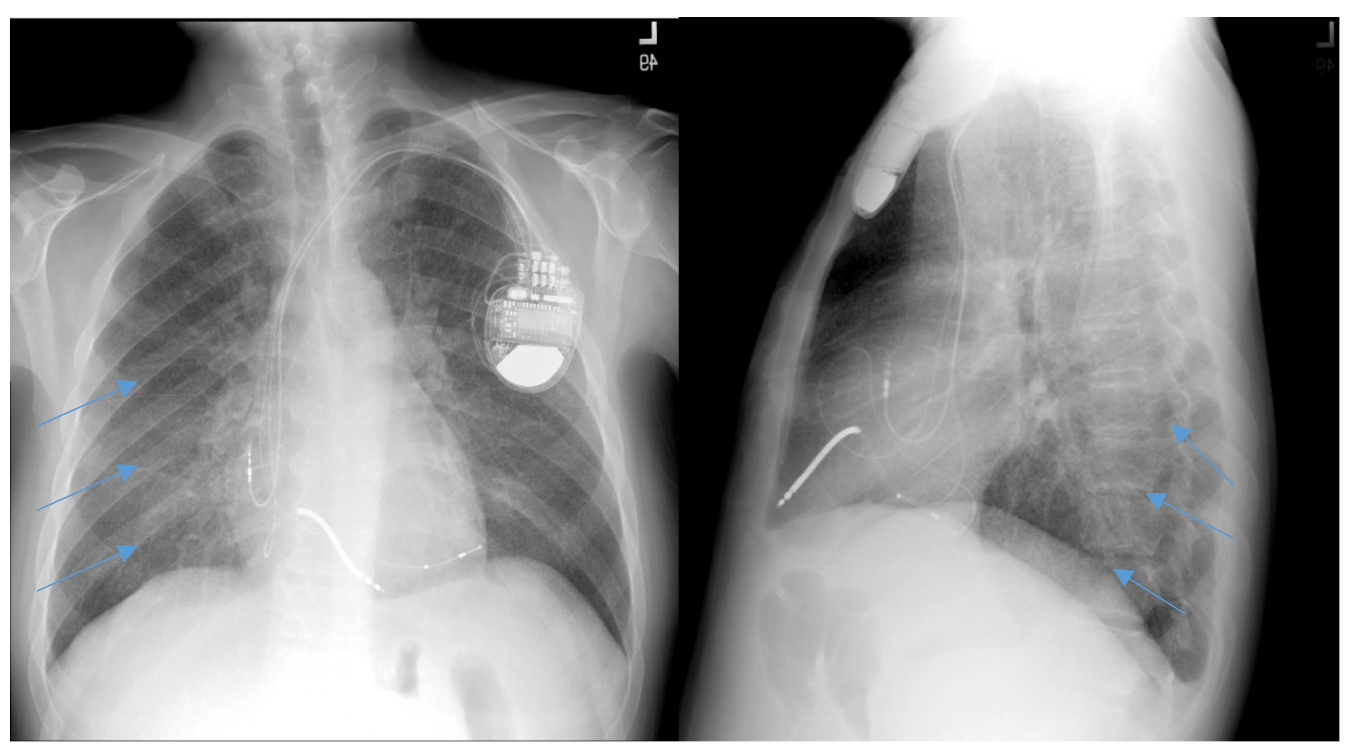

Fig. 1 Posterior anterior and lateral chest X-ray showing diffuse miliary shadowing in both lungs (Arrows). The cardiac resynchronization therapydefibrillator device and leads in place

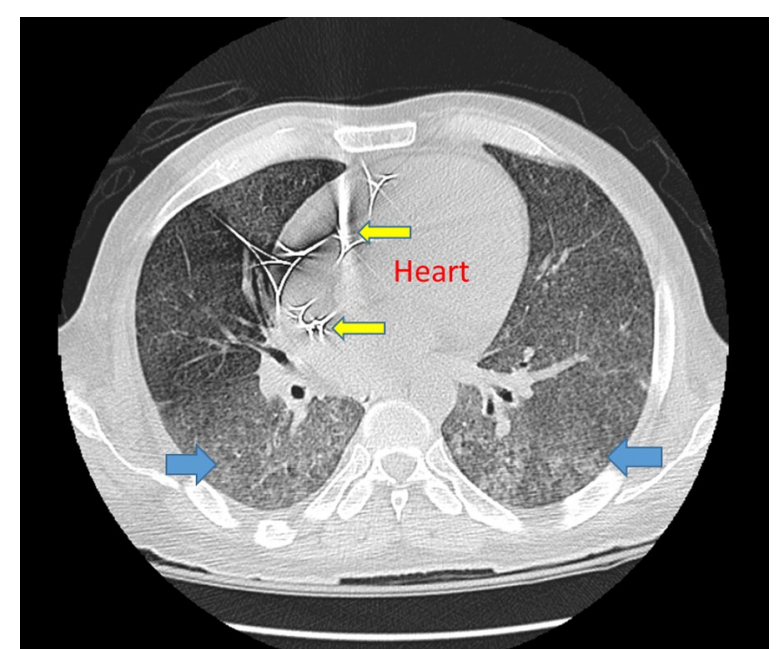

Fig. 2 Computed tomography (CT) chest axial plane showing diffuse randomly distributed ground-glass nodules (blue arrows) involving bilateral lungs consistent with military tuberculosis. Implantable cardioverter defibrillator leads seen (yellow arrows)

moving vegetations on other parts of the leads, but some thickening was seen on one segment of wire. It was very thin and could represent a fibrin/fibrous tissue deposit. No masses were seen on any of the four valves. A small pericardial effusion was seen and "tissue" lines in the visceral pericardium were seen which could be fibrin, a hematoma, or tissue related to tuberculosis pathology (Fig. 3).

The blood cultures and urine culture were all negative. The work up was negative for HACEK group
(Haemophilus species, Aggregatibacter species, Cardiobacterium hominis, Eikenella corrodens, and Kingella kingae), and other bacterial and viral infection including human immunodeficiency virus (HIV) and respiratory viruses.

Bronchoscopy and bronchoalveolar lavage were performed, and pathology examination showed a necrotizing granulomatous inflammation and special stains for AFB were positive. The culture showed Mycobacterium tuberculosis and sensitivity came back as sensitive to all first line anti-TB therapy.

His clinical course was complicated by acute renal failure with an increase in serum creatinine to $351 \mu \mathrm{mol} / \mathrm{L}$ and urea to $37 \mathrm{mmol} / \mathrm{L}$. It was felt that the cause of his renal impairment was due to cardio-renal syndrome. It improved gradually and he did not require hemodialysis. He also had confusion and was noted to have a tonic-clonic seizure disorder. He was intubated, put on mechanical ventilation and started on anti-seizure treatment with IV levetiracetam (keppra) and phenytoin. Electroencephalogram showed a severe diffuse encephalopathy with periodic epileptiform discharges and continuous slow activity, generalized (delta coma). CT brain showed a preserved gray-white matter differentiation with no evidence of acute established territorial infarction, intra-axial or extra-axial hemorrhage, hydrocephalus, mass effect, or midline shifting.

Lumbar puncture was performed and cerebrospinal fluid (CSF) analysis showed a pale yellow, slightly turbid fluid with labs of: RBC 110 (normally 0), WBC $300 \times 10^{9} / \mathrm{L}\left(0-5 \times 10^{6} / \mathrm{L}\right)$ with neutrophils 72 , band 


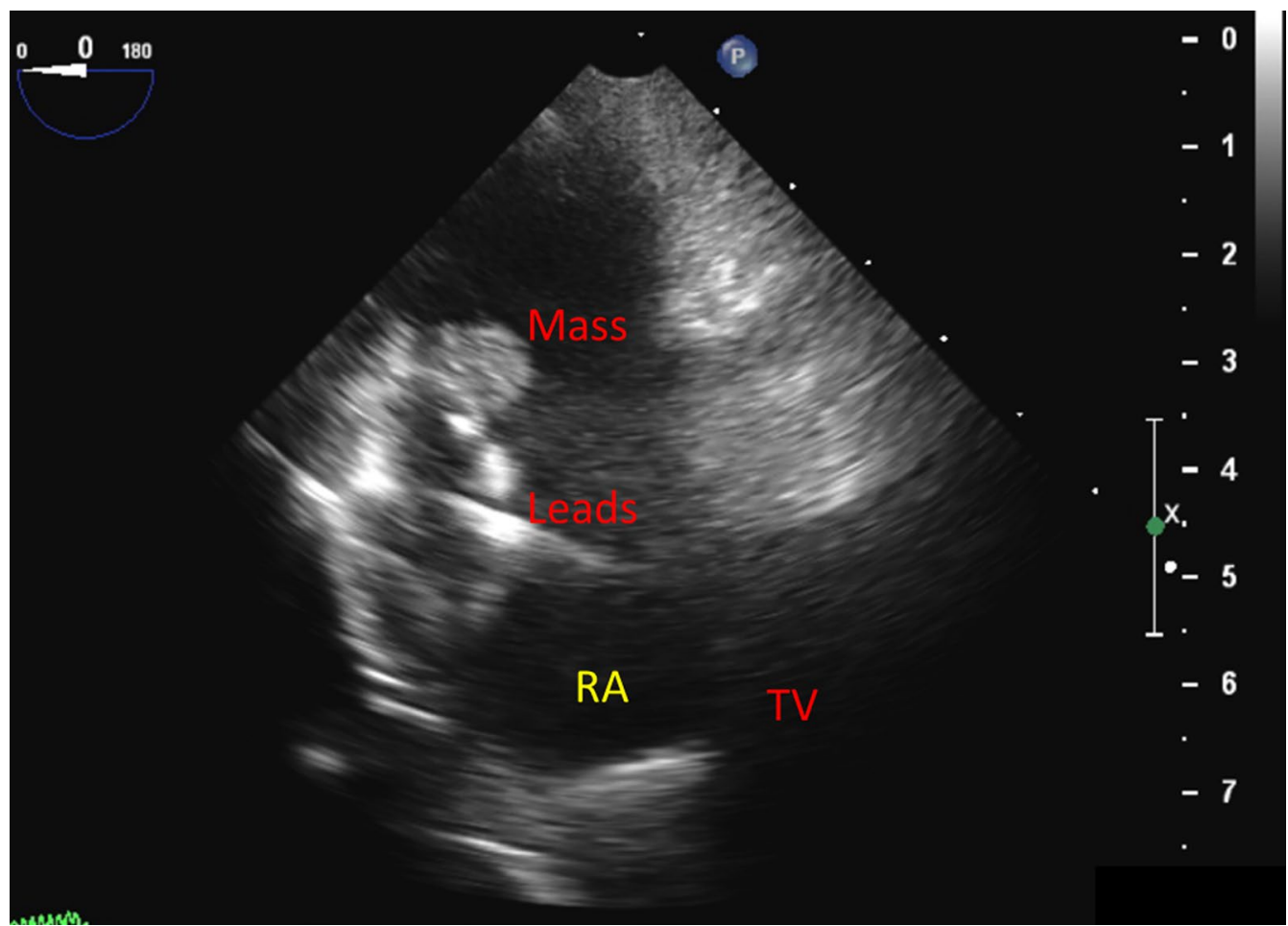

Fig. 3 Transesophageal echocardiogram at mid esophageal level showing mass in the right atrium attached to the lead

1 , lymphocytes 22, and monocytes 5. Glucose was $0.12 \mathrm{mmol} / \mathrm{L}(2.2-3.90 \mathrm{mmol} / \mathrm{L})$, and protein $3580 \mathrm{mg} / \mathrm{L}$ (150-450 mg/L). Mycobacterium tuberculosis complex DNA was positive and Mycobacterium tuberculosis complex was isolated from the CSF. These findings were consistent with TB meningitis. Furthermore, he had melena with a drop in his hemoglobin to $69 \mathrm{~g} / \mathrm{L}$. He required transfusion of two units of packed red blood cells (PRBC). Upper gastroenterology endoscopy was performed, and it revealed a duodenal ulcer, which was cauterized. His thrombocytopenia continued and platelets dropped further to $14 \times 10^{9} / \mathrm{L}$. Hematology service was involved and it was felt that his thrombocytopenia was secondary to his TB infection. Coombs test was positive and peripheral blood smear showed no significant schistocytes making thrombotic thrombocytopenic purpura (TTP) unlikely.

It was decided to remove his CRT-D device leads surgically due to the large size of the vegetations. Once he was relatively stable he was taken to the operating room and under general anesthesia a median sternotomy was performed and he was put on cardiopulmonary bypass machine. The RA was opened and the vegetation was noted to extend from the SVC to mid-RA (Fig. 4).

The vegetation was removed and sent for culture and sensitivity. The three leads were removed completely.
Cardiopulmonary bypass was weaned off gradually with no difficulty. The patient tolerated the procedure and was transferred to the Cardiac Surgery Intensive Care Unit (CSICU) on inotropic support. The microbiology test of the vegetation revealed 10 colonies of Mycobacterium tuberculosis complex. In the CSICU, he was noted to have a high-grade fever and hemodynamic instability despite maximum inotropic support. He ultimately went into a multi-organ failure and died a few days later.

\section{Discussion}

We are presenting a case of miliary tuberculosis (TB) with infective endocarditis involving cardiac resynchronization therapy device leads. We believe that this patient had a miliary TB that was complicated by infection of the CRT-D devices leads due hematogenous spread. There was no evidence of device pocket infection and miliary TB preceded the CDR-IE.

Infection of CIEDs is a serious cardiovascular disease which is associated with a high mortality. The incidence of CIEDs infection in a population-based study is 1.9 per 1000 device-years with a higher probability of infection after implantable cardioverter defibrillator (ICD) compared with permanent pacemaker (PPM) implantation [4]. The diagnosis and management of CIEDs infections are difficult [5]. 


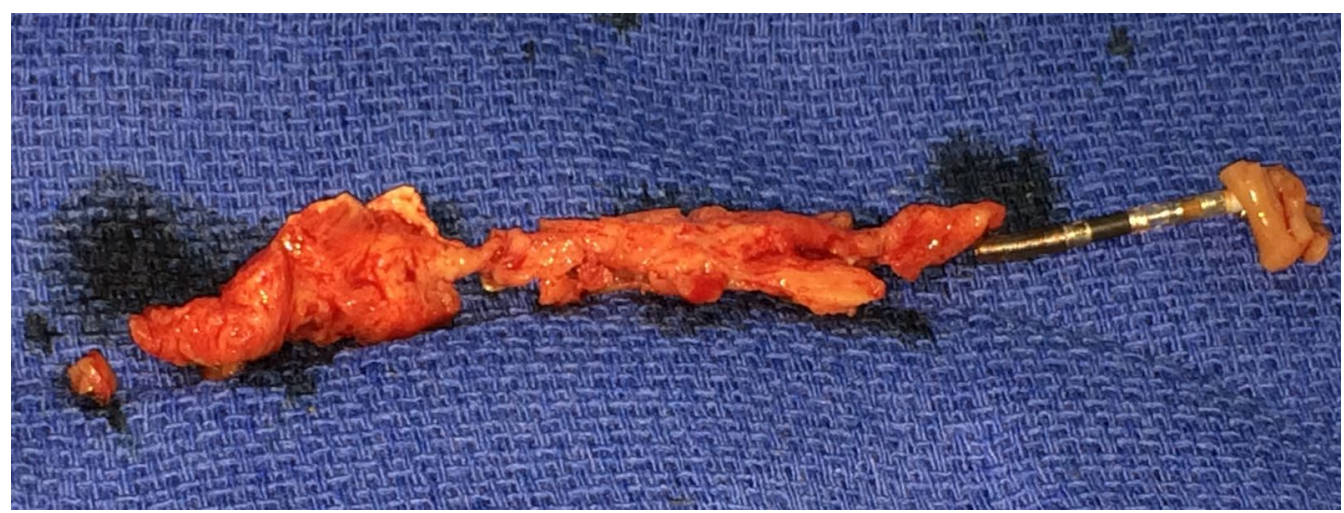

Fig. 4 Vegetation on the lead

Local device infection is defined as an infection limited to the pocket of the cardiac device and is clinically suspected in the presence of local signs of inflammation at the generator pocket, including warm site, erythema, fluctuance, wound dehiscence, erosion, tenderness or purulent drainage [6]. CDR-IE is defined as infection extending to the electrode leads, cardiac valve leaflets or endocardial surface [1]. As stated above our patient clearly had a CDR-IE secondary to hematogenous spread of the miliary TB.

Several factors have been associated with CIED infections, which may be divided firstly into patient factors such as renal failure, corticosteroid use, congestive heart failure, hematoma formation, diabetes mellitus, anticoagulation use, and fever within the $24 \mathrm{~h}$ before implantation [6-11]. Secondly, procedural factors such as the type of intervention $[12,13]$, device revisions, the site of intervention, the number of indwelling leads, the use of pre-procedural temporary pacing, failure to administer perioperative antimicrobial prophylaxis [14], and operator experience [11] all play a role.

Our patient had a CRT-D device with three leads which put him at higher risk for CIED infection.

In terms of microbiological causes of CDR-IE, Staphylococci especially Coagulase-Negative species (CoNS), accounts for $60-80 \%$ of cases in most of the reported series $[15,16]$. A variety of CoNS species have been described [6, 15]. Corynebacterium spp., Propionibacterium acnes, Gram-negative bacilli and Candida spp. are rarely identified as pathogens in CIED infection $[6,15]$.

CIED infection due to Mycobacterium species is an uncommon but a well-recognized entity.

Review of literature showed 25 case reports of CIED related infections due to Mycobacterium species [17-39], with two different Mycobacteria species in one patient [20], and three cases in one report [31]. Tables 2 and 3 show Mycobacterial infections of implanted pacemakers and ICDs respectively, as reported in literature. The infection was mostly pocket infection and rarely bacteremia with leads involvement. The infection occurred between 8 days and 20 years from the last device related procedure. It occurred with both transvenous [17, 18, 20-22, 24-27, 30, 31, 33-39] and epicardial device implantations [19, 23, 28, 29, 32]. Mycobacterium tuberculosis was reported in seven cases [18, 23, 28, 31, 36] with mostly pocket infection. In the two cases with miliary $\mathrm{TB}$, both patients died. The first patient died in hospital after a prolonged admission due to renal and respiratory failure, and recurrent ventricular fibrillation [18]. The second patient died after discharge while awaiting re-implantation of ICD in spite of the fact he had been equipped with a LifeVest [36]. The late presentation, severe systemic involvement, and underlying severe heart failure were key risk factors in our patient's ultimate outcome. Mycobacterium fortuitum was reported in nine cases [20-22, 24, 26, 27, $30,38,39$ ] with pocket infection in five cases and pocket with lead or bacteremia infection in four cases. Mycobacterium abscessus was reported in two cases $[19,33]$ with pocket infection. Mycobacterium goodii was reported in two cases $[25,29]$ with pocket infection plus bacteremia in the first case. Mycobacterium avium complex [17], and $M$. avium intracellulare complex [32] in one case causing epicardial PM and ICD pocket infection respectively. Also it was reported with M. chelonae [20], M. peregrinum [34], and M. phlei [37]. These organisms are commonly found in the environment and likely contaminate the device or pocket at the time of insertion or during surgical manipulation. Reactivation of M. tuberculosis causing a CIED infection has also been identified in some of these case reports [23, 28, 31].

The widespread use of AFB staining and mycobacterial cultures has undoubtedly increased diagnostic accuracy 


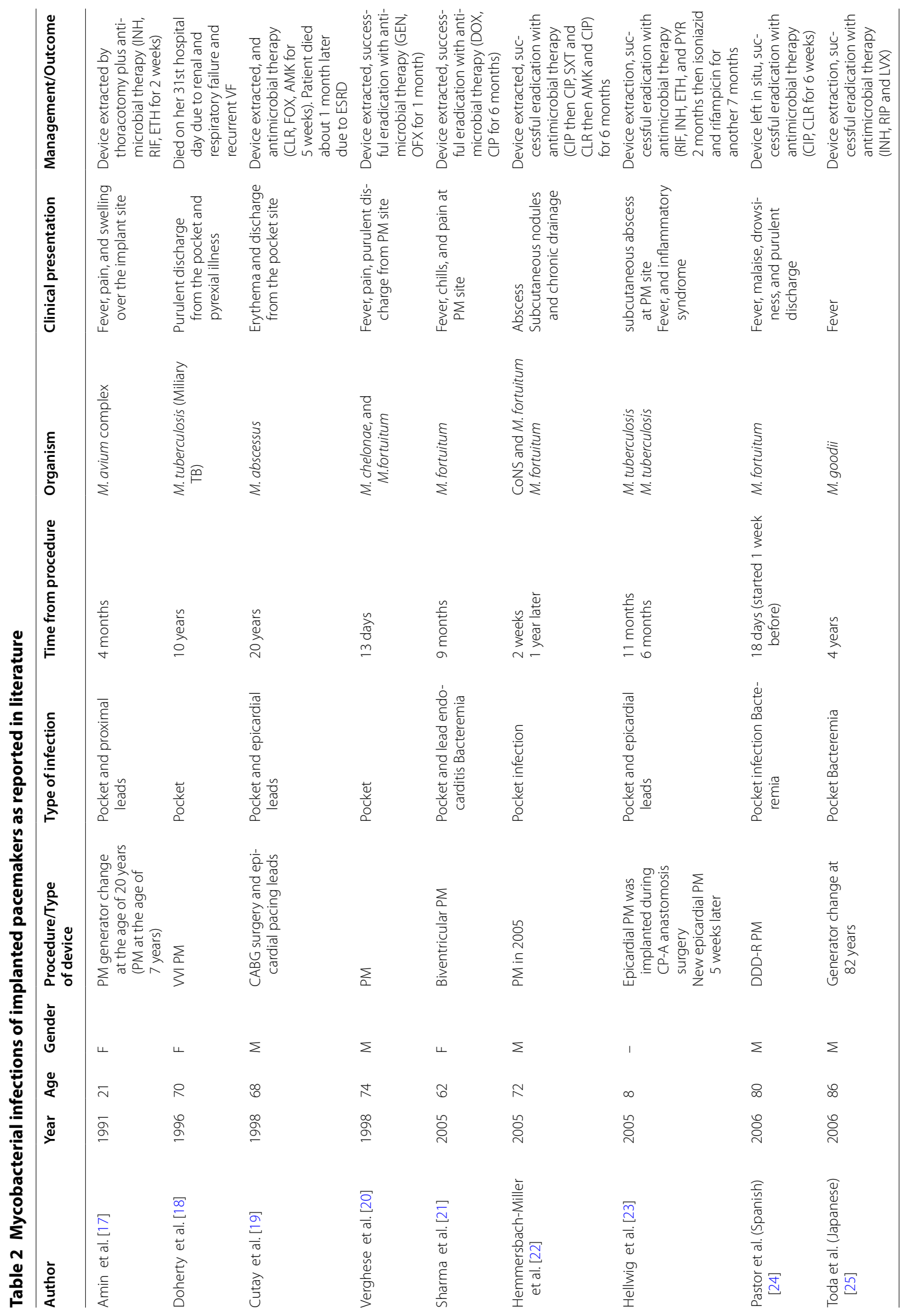




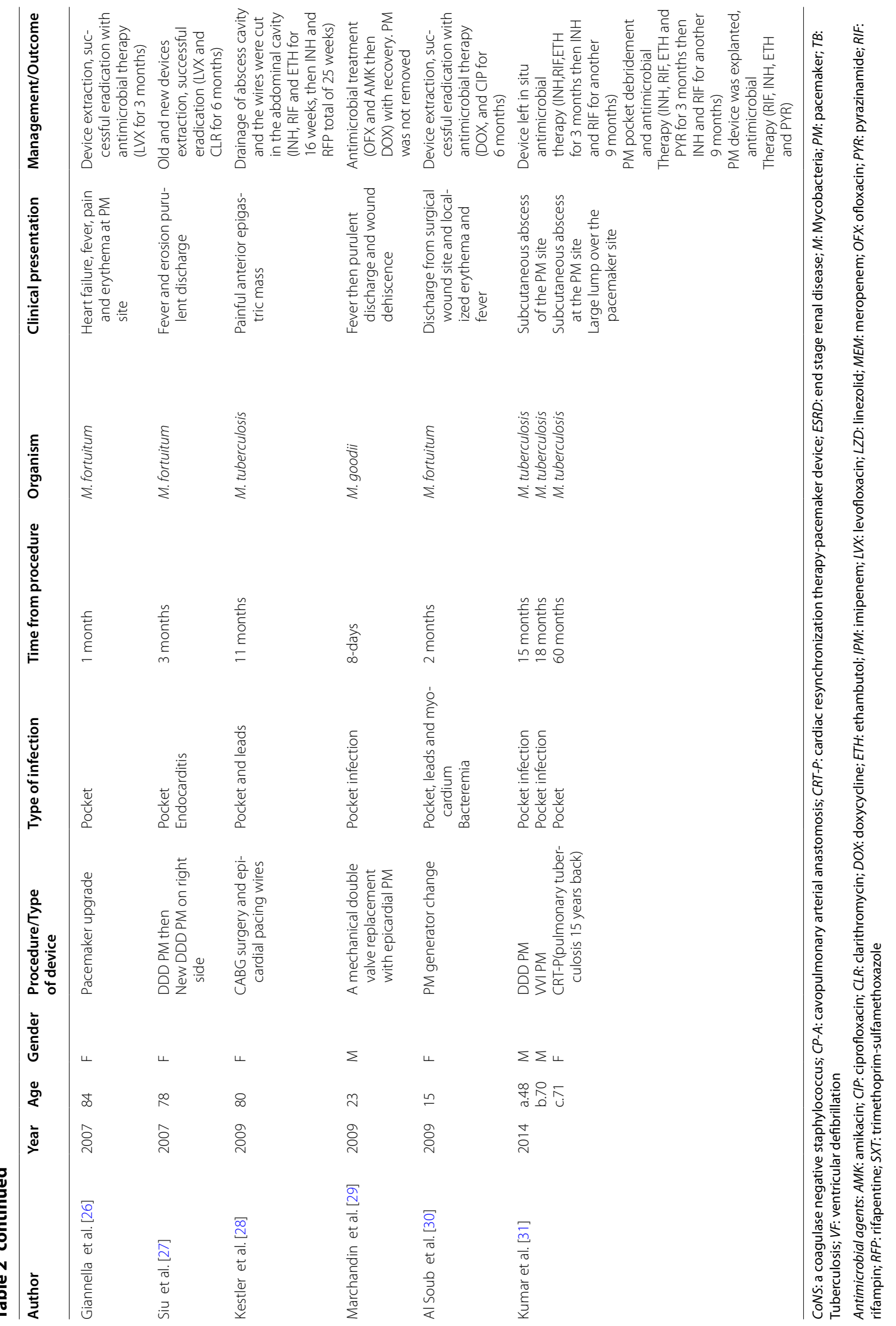




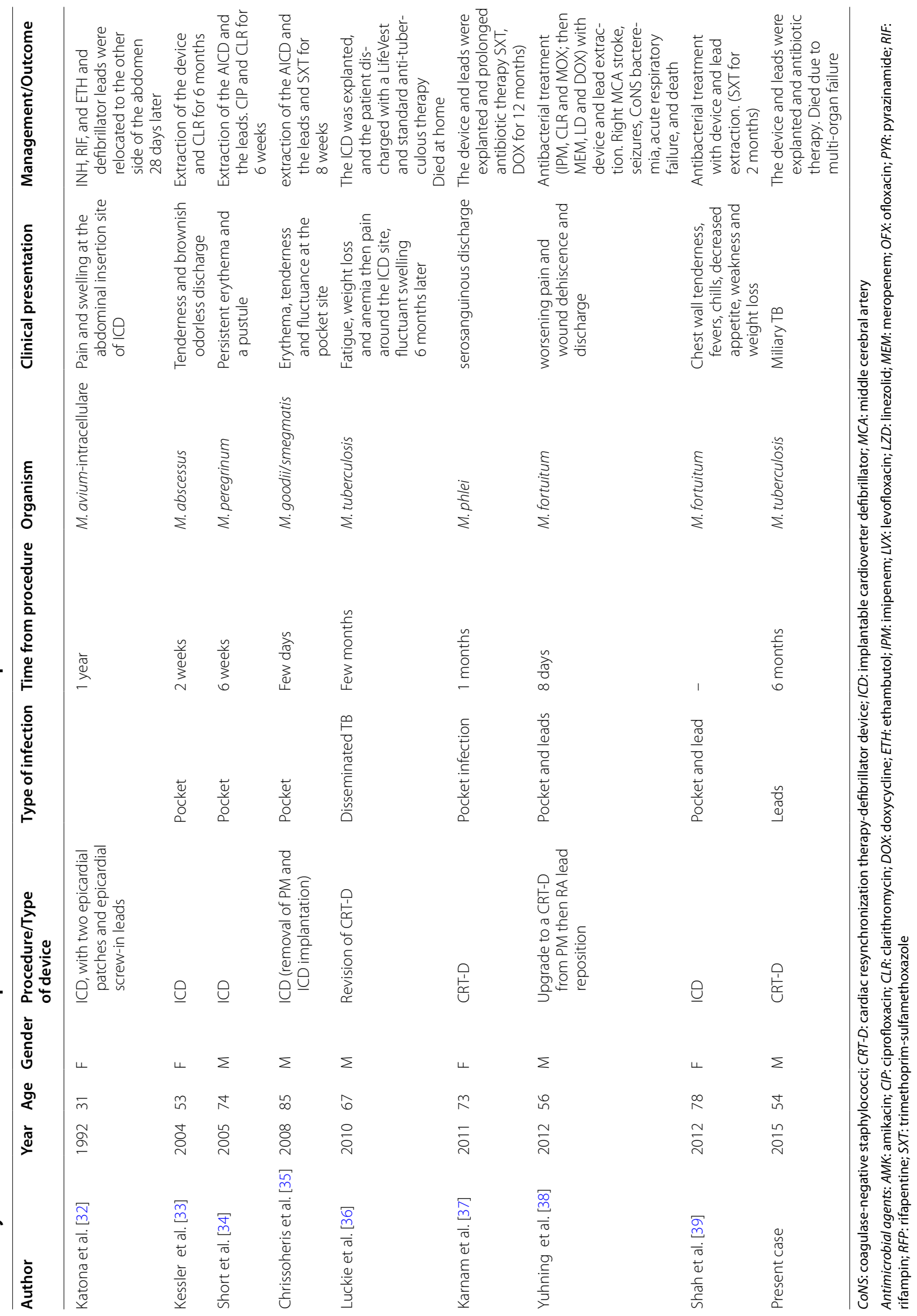


[40]. Ziehl-Neelsen staining has a sensitivity of 50-80\% while that of blood culture is approximately $98 \%[41,42]$.

Early identification of the Mycobacterium species can provide predictable antimicrobial susceptibility patterns. The best chance of cure is obtained with a combination of at least two active antimicrobials given for a minimum of 4 weeks, plus removal of the CIEDs [43].

\section{Conclusion}

CIEDs infection due to Mycobacterium species is an uncommon but a well-known entity. Early diagnosis and prompt management may result in a good outcome. In case of suspected military TB early initiation of anti-TB therapy is recommended while awaiting culture results.

\begin{abstract}
Abbreviations
${ }^{\circ} \mathrm{C}$ : celsius; AFB: acid-fast bacilli; AST: aspartate aminotransferase; CDR-IE: cardiac device-related infective endocarditis; CIEDs: cardiac implantable electronic devices; $\mathrm{CK}$ : creatine kinase; $\mathrm{CO}_{2}$ : carbon dioxide; CoNS: coagulasenegative species; CRT-D: cardiac resynchronization therapy-defibrillator; CSF: cerebrospinal fluid; CSICU: Cardiac Surgery Intensive Care Unit; CT: Computed Tomography; HACEK group: Haemophilus species, Aggregatibacter species, Cardiobacterium hominis, Eikenella corrodens, and Kingella kingae; HIV: human immunodeficiency virus; ICD: implantable cardioverter defibrillator; JVP: jugular venous pressure; LVEF: left ventricular ejection fraction; M: Myobacterium; PPM: permanent pacemaker; PRBC: packed red blood cells; RA: right atrium; SVC: superior vena cava; TB: tuberculosis; TBE: tuberculosis endocarditis; TTP: thrombotic thrombocytopenic purpura.
\end{abstract}

\section{Authors' contributions}

BAG concept/design, drafting article, critical revision of article, approval of article, statistics. HEW, MAS, JA, AAS and MH data analysis/interpretation, acquisition of data. All authors read and approved the final manuscript.

\section{Author details \\ ${ }^{1}$ Heart Centre, King Faisal Specialist Hospital and Research Centre (KFSH\&RC), MBC-16, PO Box 3354, Riyadh 11211, Saudi Arabia. ${ }^{2}$ Infectious Diseases, Department of Medicine, KFSH\&RC, Riyadh, Saudi Arabia. ${ }^{3}$ Alfaisal University, Riyadh, Saudi Arabia.}

\section{Acknowledgements}

The authors want to express their appreciation to Ms. Sandra Keating and Ms. Suzanne Tobias for editing the manuscript of this research.

\section{Competing interests}

The authors declare that they have no competing interests.

\section{Availability of data and materials}

The dataset(s) supporting the conclusions of this article is (are) included within the article [and its additional files(s)]

\section{Consent for publication}

Written informed consent was obtained from the patient's son for publication of this Case Report and any accompanying images..

\section{Ethics approval and consent to participate}

The study is approved by the Hospital Research Ethics Committee.

Received: 22 May 2016 Accepted: 15 August 2016

Published online: 24 August 2016

\section{References}

1. Habib G, Lancellotti P, Antunes MJ, Bongiorni MG, Casalta JP, Del Zotti F, Dulgheru R, El Khoury G, Erba PA, lung B, Miro JM, Mulder BJ, PlonskaGosciniak E, Price S, Roos-Hesselink J, Snygg-Martin U, Thuny F, Tornos Mas P, Vilacosta I, Zamorano JL, Document Reviewers, Erol Ç, Nihoyannopoulos P, Aboyans V, Agewall S, Athanassopoulos G, Aytekin S, Benzer W, Bueno H, Broekhuizen L, Carerj S, Cosyns B, de Backer J, de Bonis M, Dimopoulos K, Donal E, Drexel H, Flachskampf FA, Hall R, Halvorsen S, Hoen B, Kirchhof P, Lainscak M, Leite-Moreira AF, Lip GY, Mestres CA, Piepoli MF, Punjabi PP, Rapezzi C, Rosenhek R, Siebens K, Tamargo J, Walker DM. ESC guidelines for the management of infective endocarditis: the task force for the Management of Infective Endocarditis of the European Society of Cardiology (ESC). Endorsed by: European Association for Cardio-Thoracic Surgery (EACTS), the European Association of Nuclear Medicine (EANM). Eur Heart J. 2015;36(44):3075-128. doi:10.1093/ eurheartj/ehv319.

2. Liu A, Nicol E, Hu Y, Coates A. Tuberculous endocarditis. Int J Cardiol. 2013;167(3):640-5. doi:10.1016/j.ijcard.2012.08.009.

3. Gandhi T, Crawford T, Riddell J 4th. Cardiovascular implantable electronic device associated infections. Infect Dis Clin North Am. 2012;26(1):57-76. doi:10.1016/j.idc.2011.09.001.

4. Uslan DZ, Sohail MR, St Sauver JL, Friedman PA, Hayes DL, Stoner SM, Wilson WR, Steckelberg JM, Baddour LM. Permanent pacemaker and implantable cardioverter defibrillator infection: a population-based study. Arch Intern Med. 2007;167(7):669-75. doi:10.1001/archinte.167.7.669.

5. Nof E, Epstein LM. Complications of cardiac implants: handling device infections. Eur Heart J. 2013;34(3):229-36. doi:10.1093/eurheartj/ehs352.

6. Sohail MR, Uslan DZ, Khan AH, Friedman PA, Hayes DL, Wilson WR, Steckelberg JM, Stoner S, Baddour LM. Management and outcome of permanent pacemaker and implantable cardioverter-defibrillator infections. J Am Coll Cardiol. 2007;49(18):1851-9. doi:10.1016/j.jacc.2007.01.072.

7. Klug D, Balde M, Pavin D, Hidden-Lucet F, Clementy J, Sadoul N, Rey JL, Lande G, Lazarus A, Victor J, Barnay C, Grandbastien B, Kacet S. Risk factors related to infections of implanted pacemakers and cardioverter-defibrillators: results of a large prospective study. Circulation. 2007;116:1349-55. doi:10.1161/CIRCULATIONAHA.106.678664.

8. Sohail MR, Uslan DZ, Khan AH, Friedman PA, Hayes DL, Wilson WR, Steckelberg JM, Stoner SM, Baddour LM. Risk factor analysis of permanent pacemaker infection. Clin Infect Dis. 2007;45(2):166-73. doi:10.1086/518889.

9. Bloom H, Heeke B, Leon A, Mera F, Delurgio D, Beshai J, Langberg J. Renal insufficiency and the risk of infection from pacemaker or defibrillator surgery. Pacing Clin Electrophysiol. 2006;29(2):142-5. doi:10.1111/j.1540-8159.2006.00307x.

10. Lekkerkerker JC, van Nieuwkoop C, Trines SA, van der Bom JG, Bernards A, van de Velde ET, Bootsma M, Zeppenfeld K, Jukema JW, Borleffs JW, Schalij MJ, van Erven L. Risk factors and time delay associated with cardiac device infections: Leiden device registry. Heart. 2009;95(9):715-20. doi:10.1136/hrt.2008.151985.

11. Al-Khatib SM, Lucas FL, Jollis JG, Malenka DJ, Wennberg DE. The relation between patients' outcomes and the volume of cardioverter-defibrillator implantation procedures performed by physicians treating Medicare beneficiaries. J Am Coll Cardiol. 2005;46(8):1536-40. doi:10.1016/j. jacc.2005.04.063.

12. Johansen J, Nielsen J, Arnsbo P, Moller M, Pedersen A, Mortensen P. Higher incidence of pacemaker infection after replacement than after first implantation: experiences from 36,076 consecutive patients. Heart Rhythm. 2006;3:S102-3. doi:10.1016/j.hrthm.2006.02.310.

13. Gould PA, Krahn AD. Canadian Heart Rhythm Society Working Group on Device Advisories. Complications associated with implantable cardioverter-defibrillator replacement in response to device advisories. JAMA. 2006;295(16):1907-11. doi:10.1001/jama.295.16.1907.

14. DaCosta A, Kirkorian G, Cucherat M, Delahaye F, Chevalier P, Cerisier A Isaaz K, Touboul P. Antibiotic prophylaxis for permanent pacemaker implantation: a meta-analysis. Circulation. 1998;97(18):1796-801. doi:10.1161/01.CIR.97.18.1796. 
15. Bongiorni MG, Tascini C, Tagliaferri E, Di Cori A, Soldati E, Leonildi A, Zucchelli G, Ciullo I, Menichetti F. Microbiology of cardiac implantable electronic device infections. Europace. 2012;14(9):1334-9. doi:10.1093/ europace/eus044.

16. Tarakji KG, Chan EJ, Cantillon DJ, Doonan AL, Hu T, Schmitt S, Fraser TG, Kim A, Gordon SM, Wilkoff BL. Cardiac implantable electronic device infections: presentation, management, and patient outcomes. Heart Rhythm. 2010;7(8):1043-7. doi:10.1016/j.hrthm.2010.05.016.

17. Amin M, Gross J, Andrews C, Furman S. Pacemaker infection with Mycobacterium avium complex. Pacing Clin Electrophysiol. 1991;14(2 Pt 1):152-4. doi:10.1111/j.1540-8159.1991.tb05083.x.

18. Doherty JG, Rankin R, Kerr F. Miliary tuberculosis presenting as infection of a pacemaker pulse-generator pocket. Scott Med J. 1996;41 (1):20-1. doi:10.1177/003693309604100108.

19. Cutay AM, Horowitz HW, Pooley RW, Van Horn K, Wormser GP. Infection of epicardial pacemaker wires due to Mycobacterium abscessus. Clin Infect Dis. 1998;26(2):520-1. doi:10.1086/517106.

20. Verghese S, Mullaseri A, Padmaja P, Subhadra AC, Cherian KM. Pacemaker implant site caused by atypical mycobacteria. Indian Heart J. 1998;50(2):201-2.

21. Sharma S, Tleyjeh IM, Espinosa RE, Costello BA, Baddour LM. Pacemaker Infection due to Mycobacterium fortuitum. Scand J Infect Dis. 2005;37:66-7.

22. Hemmersbach-miller M, Cardenes-Santana MS, Conde-Martel A, BolanosGuerra HA, Campos-Herrer MI. Cardiac device infections due to Mycobacterium fortuitum. Can J Infect Dis Med Microbiol. 2005;16(3):183-5.

23. Hellwig T, Ou P, Offredo C, Stephany D, Bonnet D, Sidi D. Unusual chronic pacemaker infection by Mycobacterium tuberculosis in a pediatric patient. J Thorac Cardiovasc Surg. 2005;130(3):937-8. doi:10.1016/j. jtcvs.2005.04.016.

24. Pastor E, Luz Andre A, Llombart M, Chiner E. Mycobacterium fortuitum: a rare cause of pacemaker infection [Article in Spanish]. Enferm Infec Microbiol Clin. 2006;24(2):136-7.

25. Toda H, Sato K, limori M, Yamazumi T, Furuta I, Satoh A, Katsukawa C. A case of Mycobacterium goodii infection with isolation from blood and a pacemaker lead [Article in Japanese]. Kansenshogaku Zasshi. 2006;80(3):262-6.

26. Giannella M, Valerio M, Franco JA, Marin M, Bouza E, Munoz P. Pacemaker infection due to Mycobacterium fortuitum: the role of universal 16S rRNA gene PCR and sequencing. Diagn Microbiol Infect Dis. 2007;57(3):337-9. doi:10.1016/j.diagmicrobio.2006.08.010.

27. Siu CW, Cheng LC, Woo PC, Lau CP, Tse HF. A patient with relapsing pacemaker infection due to "Gram-positive bacilli". Int J Cardiol. 2007;114(2):E40-1. doi:10.1016/j.jicard.2006.07.211.

28. Kestler M, Reves R, Belknap R. Pacemaker wire infection with Mycobacterium tuberculosis: a case report and literature review. Int J Tuberc Lung Dis. 2009;13(2):272-4.

29. Marchandin H, Battistella P, Calvet B, Darbas H, Frapier JM, Jean-Pierre H, Parer S, Jumas-Bilak E, Van de Perre P, Godreuil S. Pacemaker surgical site infection caused by Mycobacterium goodie. J Med Microbiol. 2009;58(Pt 4):517-20. doi:10.1099/jmm.0.006759-0.
30. Al Soub H, Al Maslamani M, Al Khuwaiter J, El Deeb Y, Abu Khattab M. Myocardial abscess and bacteremia complicating Mycobacterium fortuitum pacemaker infection case report and review of the literature. Pediatr Infect Dis J. 2009;28(11):1032-4. doi:10.1097/INF.0b013e3181aa6592.

31. Kumar A, Agrawal T. A study of unusual pacemaker infection by Mycobacterium tuberculosis in Indian patients. Indian Pacing Electrophysiol J. 2014;14(6):291-6.

32. Katona P, Wiener I, Saxena N. Mycobacterium avium-intracellulare infection of an automatic implantable cardioverter defibrillator. Am Heart J. 1992;124(5):1380-1. doi:10.1016/0002-8703(92)90429-Y.

33. Kessler AT, Kourtis AP. Mycobacterium abscessus as a cause of pacemaker infection. Med Sci Monit. 2004;10(10):CS60-2.

34. Short WR, Emery C, Bhandary M, O'Donnell JA. Misidentification of Mycobacterium peregrinum, the causal organism of a case of bacteremia and automatic implantable cardioverter defibrillator-associated infection, due to its unusual acid-fast staining characteristics. J Clin Microbiol. 2005;43(4):2015-7. doi:10.1128/JCM.43.4.2015-2017.2005.

35. Chrissoheris MP, Kadakia H, Marieb M, Libertin C. Pacemaker pocket infection due to Mycobacterium goodii: case report and review of the literature. Conn Med. 2008;72(2):75-7.

36. Luckie M, Zaidi A, Woodhead M, Garratt C. Mycobacterium tuberculosis causing infection of an implantable biventricular defibrillator. Indian $J$ Tuberc. 2010;57:213-5.

37. Karnam S, Alla VM, Kwon J, Harbert T, Sharma A, Airey K, Mooss A. Mycobacterium phlei, a previously unreported cause of pacemaker infection: thinking outside the box in cardiac device infections. Cardiol J. 2011;18(6):687-90. doi:10.5603/CJ.2011.0034.

38. Hu Y, Bridge B, Wang J, Jovina I. Mycobacterium fortuitum causing infection of a biventricular pacemaker/implantable cardioverter defibrillator. Int J Mycobacteriol. 2012;1 (4):221-3. doi:10.1016/j.jmyco.2012.10.001.

39. Shah P, Vishnevsky A. Mycobacterium fortuitum device infection with subsequent endocarditis. The Medicine Forum. 2012;13: Article 13. http:// jdc.jefferson.edu/tmf/vol13/iss1/13.

40. El Khéchine A, Drancourt M. Diagnosis of pulmonary tuberculosis in a microbiological laboratory. Med Mal Infect. 2011;41(10):509-17. doi:10.1016/j.medmal.2011.07.012.

41. Murray SJ, Barrett A, Magee JG, Freeman R. Optimisation of acid fast smears for the direct detection of mycobacteria in clinical samples. J Clin Pathol. 2003;56(8):613-5. doi:10.1136/jcp.56.8.613.

42. Moore DA, Evans CA, Gilman RH, Caviedes L, Coronel J, Vivar A, Sanchez E, Piñedo Y, Saravia JC, Salazar C, Oberhelman R, Hollm-Delgado MG, LaChira D, Escombe AR, Friedland JS. Microscopic-observation drug-susceptibility assay for the diagnosis of TB. N Engl J Med. 2006;355(15):153950. doi:10.1056/NEJMoa055524.

43. El Helou G, Viola GM, Hachem R, Han XY, Raad II. Rapidly growing mycobacterial bloodstream infections. Lancet Infect Dis. 2013;13(2):166-74. doi:10.1016/S1473-3099(12)70316-X.

\section{Submit your next manuscript to BioMed Central and we will help you at every step:}

- We accept pre-submission inquiries

- Our selector tool helps you to find the most relevant journal

- We provide round the clock customer support

- Convenient online submission

- Thorough peer review

- Inclusion in PubMed and all major indexing services

- Maximum visibility for your research

Submit your manuscript at www.biomedcentral.com/submit
BioMed Central 